\title{
Proposal of Study Supporting System using Office365 for the Visually Impaired
}

\author{
Nobuo Ezaki ${ }^{\mathrm{a}^{*}}$, Saori HAMAGUCHI ${ }^{\mathrm{a}}$, Kenji MORIYA ${ }^{\mathrm{b}}$, \\ Mitsuhide ISHIKAWA $^{\mathrm{c}}$, Tomoaki YAMAZAKI ${ }^{\mathrm{e}}$ and Kimiyasu KIYOYA ${ }^{\mathrm{d}}$ \\ a Department of Information and Control Engineering, National Institute of Technology \\ b Department of Production Systems Engineering, National Institute of Technology, Hakodate college \\ c Tokyo Independent Living Support Center for the Visually Imparied, Japan \\ d Department of Human-Oriented Information Systems Engineering, National Institute of Technology, Kumamoto College \\ * Corresponding Author: ezaki@toba-cmt.ac.jp
}

\begin{abstract}
This paper proposes a Study Supporting System that enables the visually impaired to study IT skills using Office 365 although they are at home. The system also helps their supporters by decreasing time to commute to trainees' houses. It consists of a study supporting website and two Windows Desktop applications to study basic computer skills. The system was evaluated with subjects. The subject learned the ideal process to use the system once, then tested it following the voice of a screen reading application. As a result, it was verified that visually impaired users can study properly with it.
\end{abstract}

Keywords: Visually Impaired, Office 365, Supporting Remote Study

\section{Introduction}

There are approximately 300 thousand visually impaired people in Japan [1]. They are often employed as a masseurs, masseuses, or as administrative workers [2]. Especially for administrative work, it is necessary for them to gain IT skills. To do so, they often go to living support centers. However, there are only a few support centers mostly around metropolitan areas so there is a disparity among regions in Japan [3]. Furthermore, job trainers need to visit each trainee's house for training. They spend most of their time driving and do not have enough time to teach.

According to the Handicapped Persons' Employment Promotion Law (Japan), companies have to employ handicapped people as 2 percent of their employees [4].
Accordingly, there is a demand for the employment of handicapped people.

Efforts were previously made at developing an LMS (Learning Management System) for them with Moodle [5] [6]. However, some expertise and a server are needed to construct the system. For these reasons, it was decided that Office 365, which is an online service of Microsoft, would be used [7]. This service provides office tools, Skype for Business and OneDrive. The trainers can develop a website and storage files on a cloud server and the trainees can automatically get the files on their computers. Although the trainees are not familiar with using web browsers, they can use most of its applications. Also, it is thought that Office 365 will be a major business tool. Therefore, a study of its use is beneficial for them in getting a job.

\section{System Concept and Structure}

The trainers and the trainees can share their documents online for workplace training with this system. Therefore, the trainees can study whenever or wherever they want. Also, the trainers can check trainees' progress and write feedback on the website for each trainee. In this research, "training" means editing documents on Microsoft Office. Training documents that are being used at TILS (Tokyo Independent Living Support Center for the Visually Impaired) were used for this research.

The system consists of a Study Support Website and two Windows Desktop applications [8]. Figure 1 shows the system configuration. First, the trainees study how to type 
and browse as the first step in using a computer. After they gain basic computer skills, they start to study how to create documents and tables with Microsoft Office. The supporters provide training documents to each trainee on the Study Support Website. Synchronizing of the training documents and progress records is done automatically (Figure 2, 3). On the website, supporters can review the training online and trainees can read it as an e-mail on Microsoft Outlook (Figure 4). As a consequence of this, trainees can study and have their work reviewed as is usual at support centers even though they are at home.

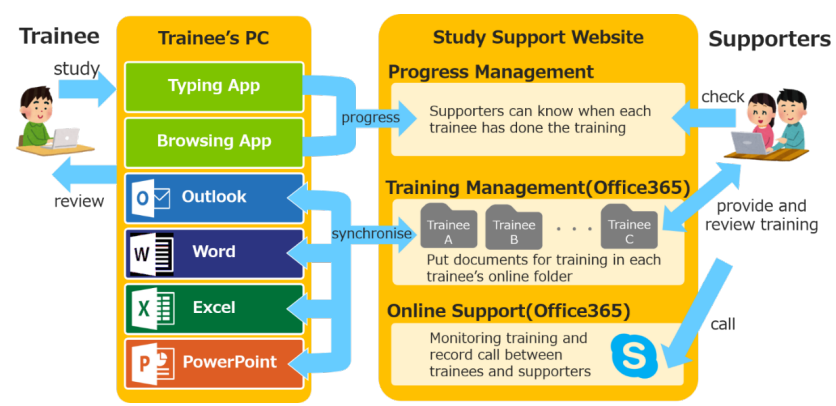

Fig. 1. The System Configuration using Office 365

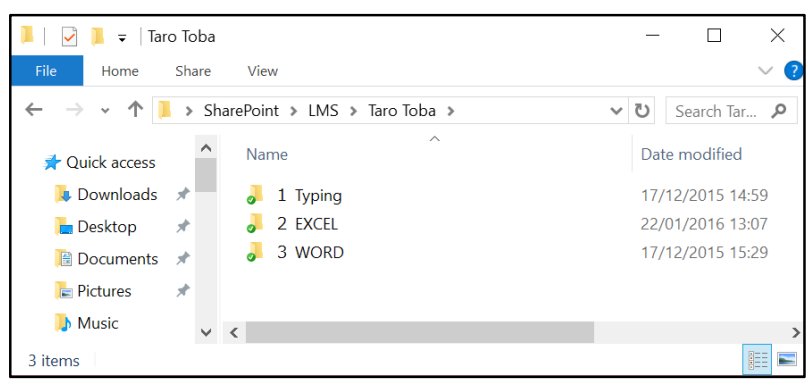

Fig. 2. Synchronized Folder (Trainee's View)

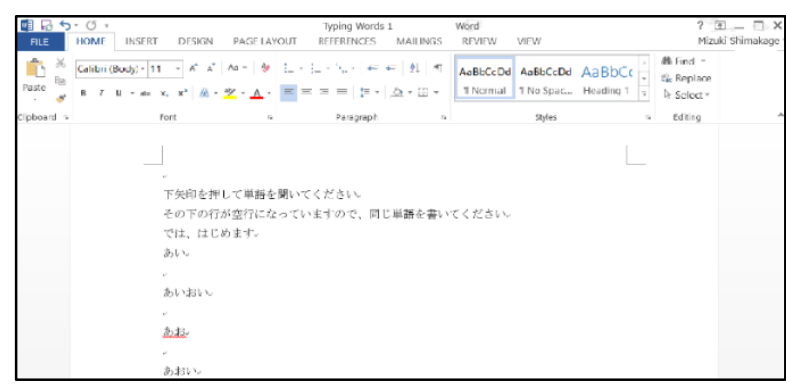

Fig. 3. Training Document

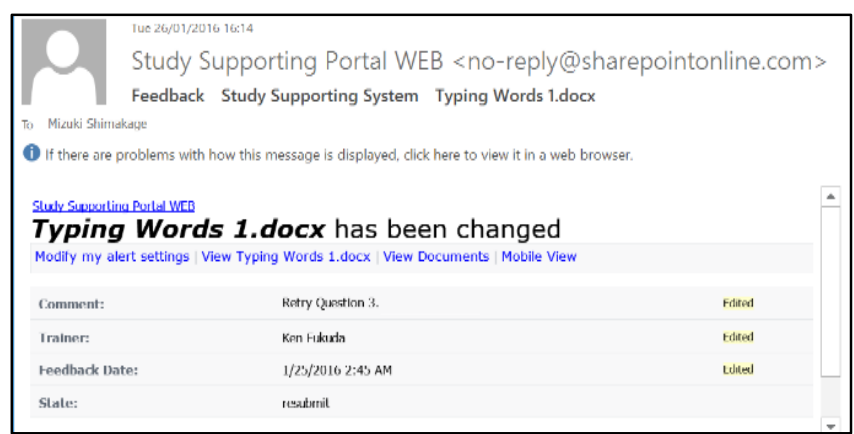

Fig. 4. Feedback Mail

The study support website is structured with "Sites" of Microsoft Office365. Sites enable the website to share documents and write review on them. Figure 5 shows the webpages for each trainee and trainers. Basically, the trainees do not have to directly use the website. If the trainees have enough skills to use Office365, they can access their own webpage of the study support website. On the webpage, they can check their progress and do the training by using Office Online (a part of the service of Office365). In addition, they can use Skype for Business to get real time support from supporters at living support centers.
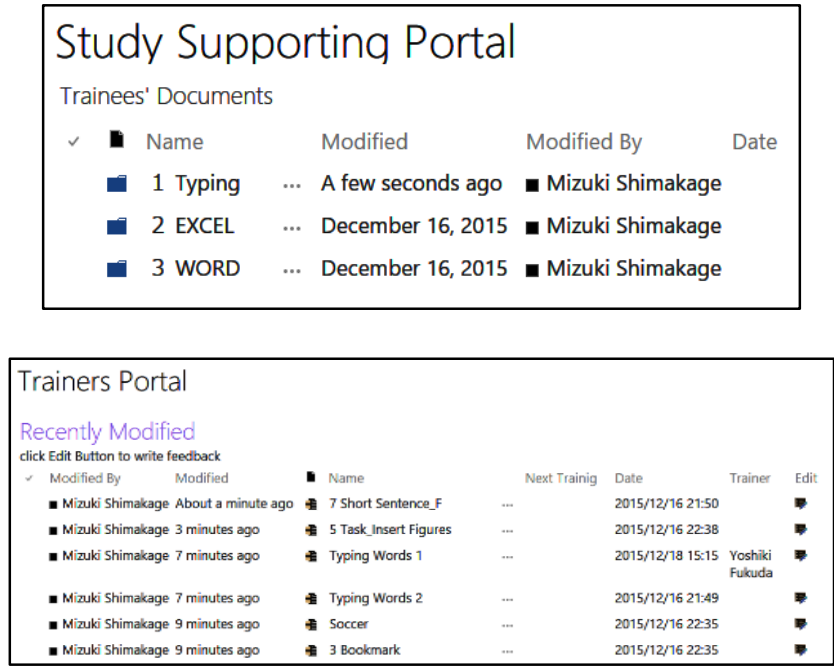

Figure 6. Appearance of the LMS 


\section{Evaluation Experiment}

The author of this paper verified whether users can study properly with the system. In this experiment, the subject was made to wear a sleeping mask to simulate the same environment experienced by visually impaired users, and the number of "steps" required to study was counted. One "step" means the subject entered a key once or multiple keys at the same time once. It was explained to the subject how to use the system during the first test. The process by which to get ideal data was also evaluated. The experiment procedure was as follows:

1. Open a specified Word file.

2. Type something on the file and save it.

3. Run Outlook and read a feedback mail from LMS.

4. Close the mail.

5. Open another specified Word file.

Table 1 shows the results of the experiment. The subject's data was getting closer to the ideal data. For the most part in this experiment, the subject was able to use the system as intended by the fifth test. Accordingly, it can be said that the system will be used properly by visually impaired users.

Table 1. Results of Evaluation Experiment

\begin{tabular}{|c|c|c|c|c|c|c|c|c|c|c|c|c|}
\hline & \multicolumn{2}{|c|}{ Ideal } & \multicolumn{2}{|c|}{ 1st time } & \multicolumn{2}{|c|}{ 2nd } & \multicolumn{2}{|c|}{3 rd } & \multicolumn{2}{|c|}{ 4th } & \multicolumn{2}{|c|}{ 5th } \\
\hline & Steps & Time & Steps & Time & Steps & Time ! & Steps & Time & Steps & Time & Steps & Time \\
\hline 1. & 6 & $30 \mathrm{~s}$ & 12 & $53 \mathrm{~s}$ & 10 & $27 \mathrm{~s}$ & 10 & $28 \mathrm{~s}$ & 10 & $24 \mathrm{~s}$ & 6 & $19 \mathrm{~s}$ \\
\hline 2. & 2 & $11 \mathrm{~s}$ & 17 & $1 \mathrm{~m} 21 \mathrm{~s}$ & 4 & $28 \mathrm{~s}$ & 4 & $17 \mathrm{~s}$ & 3 & $11 \mathrm{~s}$ & 3 & \\
\hline 3. & 5 & $34 \mathrm{~s}$ & 8 & $1 \mathrm{~m} 05 \mathrm{~s}$ & 13 & $1 \mathrm{~m} 34 \mathrm{~s}$ & 5 & $23 \mathrm{~s}$ & 8 & $39 \mathrm{~s}$ & 6 & \\
\hline 4. & 1 & $8 \mathrm{~s}$ & 6 & $33 \mathrm{~s}$ & 19 & $1 \mathrm{~m} 49 \mathrm{~s}$ & 1 & $27 \mathrm{~s}$ & 1 & $13 \mathrm{~s}$ & 1 & \\
\hline 5. & 2 & $1 \mathrm{~m} 04 \mathrm{~s}$ & 3 & $2 \mathrm{~m} 28 \mathrm{~s}$ & 28 & $4 \mathrm{~m} 06 \mathrm{~s}$ & 3 & $1 \mathrm{~m} 24 \mathrm{~s}$ & 2 & $1 \mathrm{~m} 09 \mathrm{~s}$ & 4 & $1 \mathrm{~m} 2$ \\
\hline 6. & 3 & $8 \mathrm{~s}$ & 8 & $1 \mathrm{~m} 32 \mathrm{~s}$ & 5 & $44 \mathrm{~s}$ & 9 & $1 \mathrm{~m} 38 \mathrm{~s}$ & 8 & $55 \mathrm{~s}$ & 3 & \\
\hline
\end{tabular}

\section{Supporting Method by Skype}

Figure 5 shows Supporting flow by using poposed system. At first, trainee at home starts training (ex. Word or Excel), if he/she has a question, he/she ask by Instant Message (IM) on Skype for Business. The question will be send to Trainer's groupe chat, one of the trainer who can reply at the time, will send some comments. If it can't solve the problem, on call support by using Skype for Business also can select. It's is easy to find problem for trainer by sharing trainee's screen. We set up short cut program by powershell to easy connect to Voice chat.

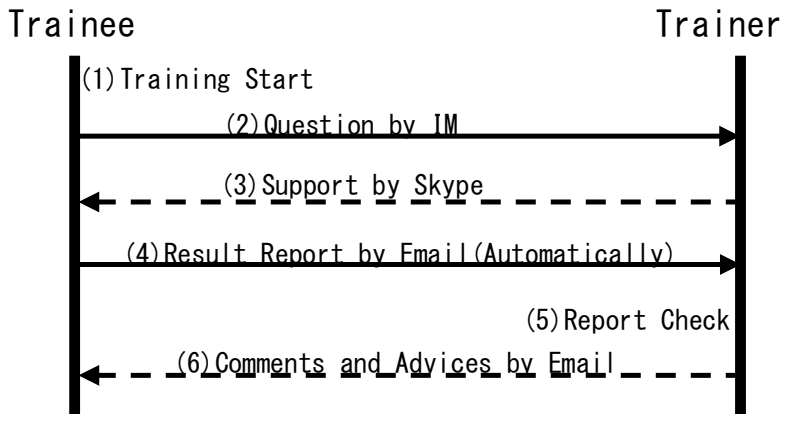

Fig. 5. Supporting flow by proposed system

After training, result report will be sent to trainer by Email automatically. The trainer will follow up the trainee with report by using Email or IM.

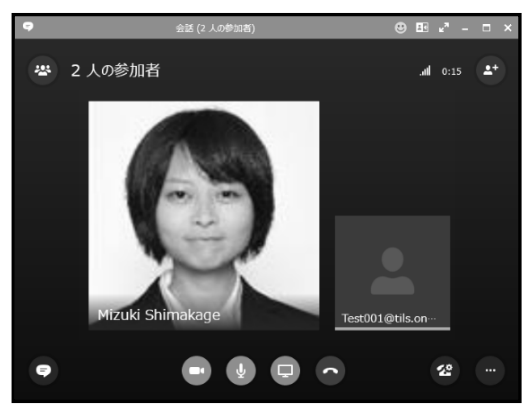

Fig. 6. Voice support by Skype for Business

\section{Conclusion and Planned Activities}

In conclusion, the Study Support System was developed to make the training smooth even though the trainee and supporter are far away from each other. To use the system, the typing and browsing training applications were also developed for the visually impaired who do not have basic computer skills. Now the synchronizing function of trainees' progress between the website and the typing/ browsing application is being developed.

Further studies are needed in order to make the system easier to use. Therefore, another evaluation experiment on the whole system will be conducted at TILS. Also, for the needs of new training programs of the typing application, Online Shopping Training and Using Search Engine Training are being developed.

\section{Acknowledgment}

A part of this study was supported by a Grant-in-Aid for Scientific Research (N.E. No.15K01111) from the Japan 
Society for the Promotion of Science.

\section{References}

(1) Policy Planning Division, Department of Health and Welfare for Persons with Disabilities, Social Welfare and War Victims' Relief Bureau, Ministry of Health, Labour and Welfare (2008). Survey on persons with physical disability. Statistic Bureau, Ministry of International Affairs and Communications.

(2) National Institute of Vocational Rehabilitation (2013). Research on Intra-company Activities to Enhance the Scope of Administrative Work of the Visually Impaired. http://www.nivr.jeed.or.jp/download/houkoku/houkoku 116_summary.pdf

(3) Rehabilitation Center of Visual Impairment (2014). Research on Rehabilitation Centers of the Visually Impaired. Nippon Lighthouse.

(4) Ministry of Health, Labour and Welfare (2013). Overview of Changes of Handicapped Persons' Employment Promotion Law.

http://www.mhlw.go.jp/bunya/koyou/shougaisha_h25/d 1/kaisei02.pdf

(5) Moodle (2015).AboutMoodle. https://docs.moodle.org/30/en/About_Moodle

(6) Miyu Kinoshita, Saori Hamaguchi, Nobuo Ezaki, Mitsuhide Ishikawa (2014). The System Design of Supporting Educational Program for Blind. IEICE Technical Report, Vol.113, No.481, WIT2013-72. pp.31-36.

(7) Microsoft (2016). Explore Office 365. https://products.office.com/en-us/business/exploreoffice-365-for-business

(8) Azusa Fujita, Mizuki Shimakage, Nobuo Ezaki, Mitsuhide Ishikawa, Tomoaki Yamazaki, Yasuhiro Hama(2015). Browsing Training Application for the Visually Impaired. Japan AT Forum 2015. pp.11-12 